\title{
Effect of pH and Electrolysis Time on Removal of Reactive Black B dye by Electrochemical Treatment
}

\author{
S.Manikandan ${ }^{1}$, R.Saraswathi ${ }^{2}$ and A.Mohammed Siraj Ansari ${ }^{3}$ \\ ${ }^{1}$ PG scholar, ${ }^{2}$ Associate Professor, ${ }^{3}$ Assistant Professor \\ Coimbatore Institute of Technology, Coimbatore, Tamil Nadu, India \\ E-Mail: manikandans877@gmail.com
}

\begin{abstract}
The electrochemical treatment was an effective technique in dye processing and it can be enforced to remove color from dye solution. An Experimental setup was made for electrochemical treatment of synthetically prepared Reactive Black $B$ dye in batch mode operation using aluminum electrodes. Based on probability the operating parameters such as $\mathbf{p H}$, Concentration, Electrolysis time, Retention time were determined from which the color removal efficiency (CRE) is optimized. The maximum color removal efficiency of Reactive black $B$ dye was achieved at $98.23 \%$ for the concentration of $10 \mathrm{mg} / \mathrm{l}$.
\end{abstract}

Keywords: Reactive Black B, Aluminum, Color, pH, Efficiency

\section{INTRODUCTION}

Textile industries are one of the major areas that have an importance throughout the world. However, off recent, the industry has been the epicenter of a massive pollution problem, worldwide. Mainly, pollution in the textile waste water comes from the dyeing and finishing processes. Before water is released into the nearest water body it is essential that it is treated properly in order to ensure that there is significant reduction in the level of pollutants. Releasing the untreated colored water can cause the environmental severe effects surface and subsurface water bodies. The dye can be classified as Acid, Direct, Azoic, Sulphur, Reactive, Basic, Vat, and metal complex dyes ${ }^{[1]}$.More than 3600 textile dyes are being manufactured by the various industries today. The textile industries use 8000 and above chemicals in various processing including printing and dyeing ${ }^{[19]}$. The Decolonization is achievable using one or combination of the Adsorption, Filtration, and Precipitation, Chemical degradation, Photo degradation and biodegradation methods. The Electrochemical color removal from waste water occurs by a combination of adsorption and chemical reduction. In electrocoagulation no more coagulant has been added so the salinity of treated wastewater should be controlled.

Electrocoagulation is compact and effective method to treat various wastewaters like as textile dye water ${ }^{[2]}$, landfillleachate ${ }^{[13]}$. Tannerywastewater ${ }^{[6]}$, oil and water emulsion ${ }^{[12]}$, this experimental study deals with the electrochemical treatment of synthetically prepared Reactive Black B dye from aluminum electrodes.

\section{A. Electrocoagulation mechanism}

Three main processes occurring in the Electrocoagulation process like as;
1. Electrolytic Reaction at the electrode surface,

2. Formation of coagulants in the aqueous phase,

3. Adsorption of soluble and colloidal pollutants on coagulants, and removed by sedimentation or flotation ${ }^{[16]}$, Anode:

Cathode:

$$
\mathrm{Al} \rightarrow \mathrm{Al}_{3}+3 \mathrm{e}^{-}
$$

$$
3 \mathrm{H}_{2} \mathrm{O}+3 \mathrm{e} \rightarrow 3 / 2 \mathrm{H}_{2}+3 \mathrm{OH}^{-}
$$

Generally textile wastewater containing chlorine components, which may cause further reaction, occurs in the electrocoagulation process. During the electrocoagulation presents of chlorine atoms oxidizing the organic components in wastewater and increase the color removal efficiency.

$$
2 \mathrm{Cl}+\mathrm{Cl}_{2}+2 \mathrm{e}^{-}
$$

The cathode has been electrochemically affected by $\mathrm{OH}^{-}$ions due to release of $\mathrm{H}_{2}$ gases in the solution. $\mathrm{H}_{2}$ gas generation rate it depends up on the $\mathrm{pH}$ of the solution (Picard et al., 2000). $\mathrm{Al}_{(\mathrm{aq})}{ }^{3+}$ and $\mathrm{OH}^{-}$ions generated by reactions (1) and (2) and it forms monomeric specious as $\mathrm{Al}(\mathrm{OH})_{2}{ }^{+}, \mathrm{Al}(\mathrm{OH})_{2}{ }^{+}$, $\mathrm{Al}(\mathrm{OH})_{4}{ }^{-} \mathrm{A}_{12}(\mathrm{OH})_{24}{ }^{+}, \mathrm{Al}(\mathrm{OH})_{4}$ and polymeric specious such as $\mathrm{A}_{16}(\mathrm{OH})_{15}{ }^{3+}, \quad \mathrm{Al}_{7}(\mathrm{OH})_{17^{4}}, \mathrm{~A}_{18}(\mathrm{OH})_{20}{ }^{4+}, \quad \mathrm{Al}_{13} \mathrm{O}_{4}(\mathrm{OH})_{24}{ }^{7+}$ and $\mathrm{Al}_{13}(\mathrm{OH})_{34}{ }^{5+}$ which finally transforms into $\mathrm{Al}(\mathrm{OH})_{3}$ according to complex precipitation kinetics ${ }^{[11]}$. Two major mechanisms is involved in the electrocoagulation process such as precipitation and adsorption, those mechanisms have been depends on the $\mathrm{pH}$ of the solution. Flocculation in lower $\mathrm{pH}$ range considered as precipitation and higher range is considered as the adsorption ${ }^{[15]}$.

TABLE I CHARACTERISTICS OF REACTIVE BLACK B DYE

\begin{tabular}{|c|c|}
\hline Dye & Reactive Black B \\
\hline Appearance & Powder \\
\hline Color & Black \\
\hline Odor & None \\
\hline Dye group & Anionic \\
\hline$\lambda \max$ & $591 \mathrm{~nm}$ \\
\hline
\end{tabular}




\section{MATERIALS AND METHEDOLOGY}

Reactive Black B dye was purchased from Indian dyes Tirupur, It is water soluble anionic dye used for dyeing silk, woolen and nylon in textile industries. The general characteristics and structures ${ }^{[11]}$ of dye is listed in below Table 1.The experiment carried out effect of $\mathrm{pH}$, Concentration, Electrolysis time, Retention time with synthetically prepared Reactive Black-B dye. The experiment was studied under batch mode operation in $500 \mathrm{ml}$ beaker shown in fig 1 . Two electrodes were used. Both the electrodes are made of aluminum connected to monopolar series. This electrode was connected to DC variable power supply providing $0-30 \mathrm{~V}(0-$ 5 ampere) potentiometric power supply.

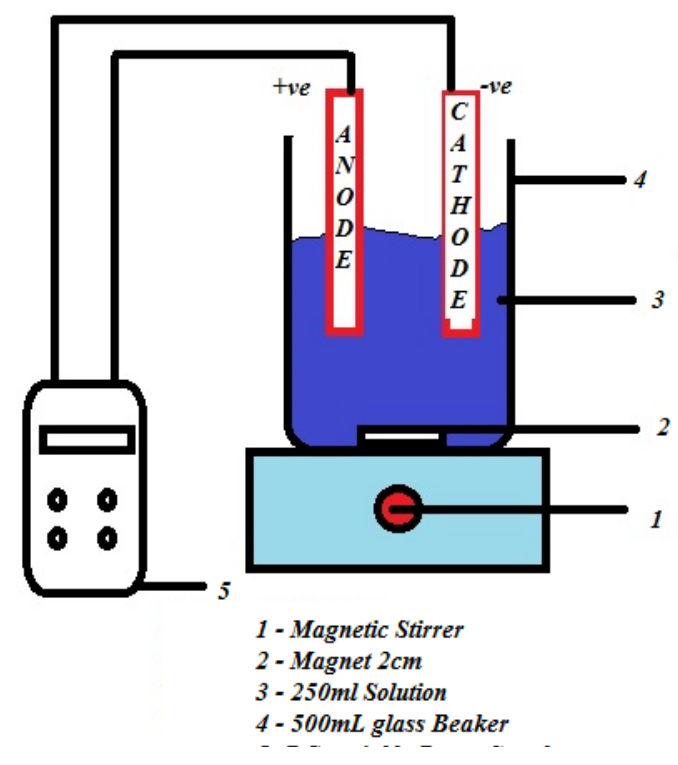

Fig. 1 Electrocoagulation reactor

The solution in the beaker was agitated by magnetic stirrer having a dimension of $2 \mathrm{~cm}$, for maintaining uniform concentration. The dimensions of anode and cathode are $10 \mathrm{~cm}$ $\mathrm{x} 5 \mathrm{~cm} \times 0.1 \mathrm{~cm}$ (Length $\mathrm{x}$ Breadth $\mathrm{x}$ Thickness) and it is submerged into $4.5 \mathrm{~cm}$ in the solution, and the submerged area of the electrode surface is $22.5 \mathrm{~cm} 2$. The spacing between the two electrodes was maintained at $3 \mathrm{~cm}$. The agitation speed of the magnetic stirrer was maintained at 300rpm and current density was maintained 1.5ampere. After the process, the impurities in the electrodes were removed by dipping the electrode in $100 \mathrm{ml}$ of $0.1 \mathrm{~mole}$ HCL. The solid surface of the electrode was then thoroughly washed and air dried before weighing. $\mathrm{pH}$ of the Reactive Black $\mathrm{B}$ dye was adjusted by adding Sodium hydroxide $(\mathrm{NaOH}) \quad 0.1 \mathrm{~N}$ and Hydrochloric acid (HCL) $0.1 \mathrm{M}$ respectively. Conductivity of the solution was changed by adding necessary amount of sodium chloride. The dye concentration was analyzed by using double beam UV spectrophotometer and the wavelength of the dye was fixed as $591 \mathrm{~nm}^{[1]}$.

Calibration:The calibration curve was prepared from 0$50 \mathrm{mg} / \mathrm{l}$ at every $5 \mathrm{mg} / \mathrm{l}$ of the solution and it based on the above mentioned wavelength based absorbance value and it shown fig 2. The colour removal efficiency was calculated using the following equation

$$
\mathrm{CRE}=\frac{\mathrm{Co}-\mathrm{Ci}}{\mathrm{Co}} \times 100
$$

Where,

$\mathrm{CRE}=$ colour removal efficiency,

$\mathrm{Co}=$ Final Concentration,

$\mathrm{Ci}=$ Initial Concentration

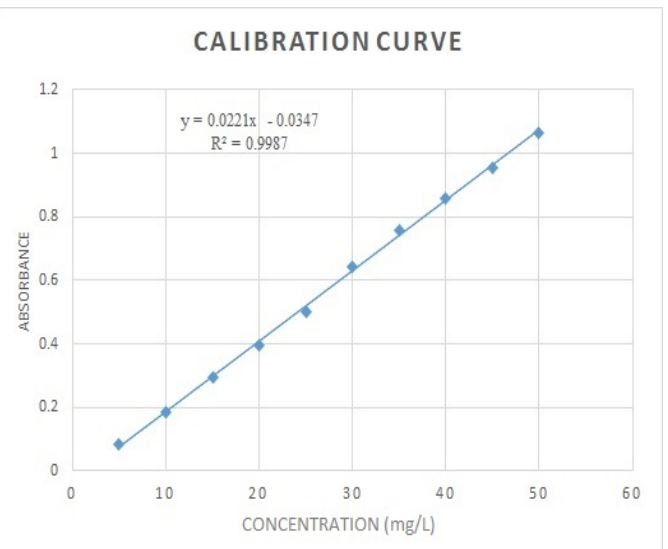

Fig. 2 Calibration Curve

\section{RESULTS AND DISCUSSION}

\section{A. Effect of $p H$}

The colour removal of the solution was carried out using the $\mathrm{pH}$ variation of 4, 7 and 9 respectively. For $\mathrm{pH}$ is 2,4,7,9 and 11 the colour removal efficiency was obtained as $69.31 \%$, $87.69 \%, 97.39 \%, 98.16 \%$ and $98.23 \%$ respectively as mentioned in fig 3. When $\mathrm{pH}$ lies between 4-9 the electrodes generate $\mathrm{Al}^{3+}$ and $\mathrm{OH}^{-}$ions leading monomeric and polymeric reactions forming complex state of $\mathrm{A}_{13}(\mathrm{OH})_{3}$ resulting higher removal efficiency. In order to increase the $\mathrm{pH}$ of sample higher amount of $\mathrm{NaOH}$ is added that produce salinity henceforth neutral $\mathrm{pH}$ of 7 is adopted in this experiment.

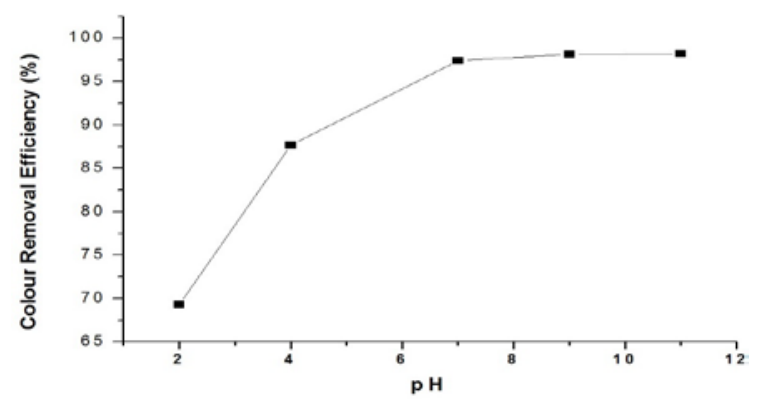

Fig. 3 Electrolysis time $=30$ minutes, Retention time $=150$ minutes, Concentration $=10 \mathrm{mg} / \mathrm{L}$.

\section{B. Electrolysis time}

Electrolysis time is the main parameter in electrocoagulation, which represents the cost of power consumption when adopting pilot scale set-up. The colour removal efficiency depends on generation of $\mathrm{Al}_{3}{ }^{+}$and $\mathrm{OH}^{-}$ions. $\mathrm{Al}_{3}{ }^{+}$ions 
production was determined by the Electrolysis time. Different Electrolysis time was carried out between 5-30 minutes and CRE was monitored for every 5 minutes interval of time. When electrolysis time was between 5-15 minutes the Colour removal efficiency was achieved to 30-60\%.At the end of 30 minutes colour removal efficiency was attained to be $98.23 \%$ that was mentioned in figure 4.

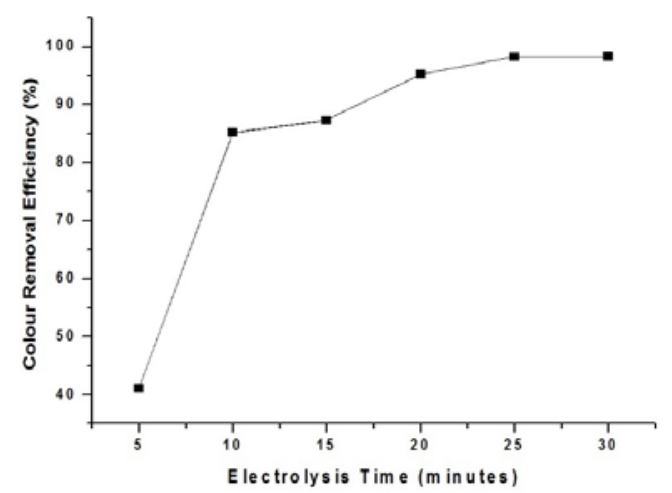

Fig. $4 \mathrm{pH}=7$, Retention time $=150$ minutes, Concentration $=10 \mathrm{mg} / \mathrm{L}$.

\section{CONCLUSION}

The experimental setup is highly suitable for treating the synthetically prepared Reactive black B dye. The maximum colour removal efficiency of $98.23 \%$ was achieved at $\mathrm{pH} 11$, concentration of $10 \mathrm{mg} / \mathrm{L}$, electrolysis time of 30 minutes and retention time of 150 minutes. Further research will be carried out on Effect of concentration, Retention time, Electrical conductivity, and Current Density.

\section{REFERENCES}

[1] V.Khandegar andA. K. Saroha, "Electrochemical treatment of textile effluent containing Acid Red 131 dye”,Journal of Hazardous, Toxic, and Radioactive Waste, Vol. 18, No. 1, pp. 38-44, 2013.

[2] M.Chafi, B.Gourich, A. H.Essadki, C.Vial and A.Fabregat, "Comparison of electrocoagulation using iron and aluminium electrodes with chemical coagulation for the removal of a highly soluble acid dye. Desalination", Vol. 281, 285-292, 2011.

[3] V.Khandegar andA. K. Saroha, "Electrochemical treatment of distillery”,2012.
[4] "Spent wash using aluminum and iron electrodes",Chinese Journal of Chemical Engineering,Vol. 20, No. 3, pp. 439-443.

[5] V.Khandegar andA. K. Saroha, "Effect of Electrode Shape and Current Source on Performance of Electrocoagulation",Journal of Hazardous, Toxic, and Radioactive Waste, Vol. 20, No. 1, 06015001, 2015.

[6] J. W.Feng, Y. B.Sun, Z.Zheng,J. B.Zhang,L. I.Shu and Y. C. Tian, "Treatment of tannery wastewater by electrocoagulation",Journal of Environmental Sciences, Vol. 19, No. 12, pp. 1409-1415, 2007.

[7] K.Mansouri, A.Hannachi,A.Abdel-Wahab andN.Bensalah, "Electrochemically dissolved aluminum coagulants for the removal of natural organic matter from synthetic and real industrial wastewaters”,Industrial \& Engineering Chemistry Research, Vol. 51, No. 5, pp. 2428-2437, 2012.

[8] A. K.Golder, N.Hridaya, A. N.Samanta andS.Ray, "Electrocoagulation of methylene blue and eosin yellowish using mild steel electrodes”,Journal of hazardous materials, Vol. 127, No. 1-3, pp. 134140, 2005.

[9] M.Bayramoglu,M.Kobya,O. T.Can andM.Sozbir, “Operating cost analysis of electrocoagulation of textile dye waste water",Separation and Purification Technology, Vol. 37, No. 2, pp. 117-125, 2004.

[10] M. M.Ayad andA. A. El-Nasr, "Adsorption of cationic dye (methylene blue) from water using polyaniline nanotubes base",The Journal of Physical Chemistry C, Vol. 114, No. 34, pp. 14377-14383, 2010.

[11] Ü. D.Gül, "Treatment of dyeing wastewater including reactive dyes (Reactive Red RB, Reactive Black B, Remazol Blue) and Methylene Blue by fungal biomass”, Water SA, Vol. 39, No. 5, pp. 593-598, 2013.

[12] P.Canizares,F.Martínez,C.Jiménez, C.Sáez andM. A. Rodrigo, "Coagulation and electrocoagulation of oil-in-water emulsions", Journal of Hazardous Materials, Vol. 151, No. 1, pp. 44-51, 2008.

[13] F.Ilhan, U.Kurt, O.Apaydin andM. T. Gonullu, "Treatment of leachate by electrocoagulation using aluminum and iron electrodes", Journal of hazardous materials, Vol. 154, No. 1-3, pp. 381-389, 2008.

[14] M.Kobya, O. T. Can andM.Bayramoglu, "Treatment of textile wastewaters by electrocoagulation using iron and aluminum electrodes”,Journal of hazardous materials, Vol. 100, No. 1-3, pp. 163178, 2003.

[15] O. T.Can, M.Kobya, E.Demirbas andM.Bayramoglu, "Treatment of the textile wastewater by combined electrocoagulation”,Chemosphere, Vol. 62, No. 2, pp. 181-187, 2006.

[16] O. T. Can,M.Bayramoglu andM.Kobya, "Decolorization of reactive dye solutions by electrocoagulation using aluminum electrodes",Industrial \& engineering chemistry research, Vol. 42, No. 14, pp. 3391-3396, 2003.

[17] V.Kuokkanen, T.Kuokkanen, J.Rämö andU. Lassi, "Recent applications of electrocoagulation in treatment of water and wastewater-a review”,Green and Sustainable Chemistry, Vol. 3, No. 02, pp. 89, 2013.

[18] N.Mohan,N.Balasubramanian andC. A.Basha, "Electrochemical oxidation of textile wastewater and its reuse",Journal of hazardous materials, Vol. 147, No. 1-2, pp. 644-651, 2007.

[19] R.Kant, "Textile dyeing industry an environmental hazard", Natural science, Vol. 4, No. 1,pp. 22-26, 2012. 